\title{
Review Article \\ Musculoskeletal Regenerative Engineering: Biomaterials, Structures, and Small Molecules
}

\author{
Roshan James $^{1,2}$ and Cato T. Laurencin ${ }^{1,2,3}$ \\ ${ }^{1}$ Department of Orthopaedic Surgery, University of Connecticut Health Center, 263 Farmington Avenue, Farmington, \\ CT 06030, USA \\ ${ }^{2}$ The Raymond and Beverly Sackler Center for Biomedical, Biological, Engineering and Physical Sciences, \\ University of Connecticut Health Center, 263 Farmington Avenue, Farmington, CT 06030, USA \\ ${ }^{3}$ Department of Biomedical Engineering, Chemical and Biomolecular Engineering, Materials Science and Engineering, \\ University of Connecticut, Storrs, CT 06269, USA
}

Correspondence should be addressed to Cato T. Laurencin; laurencin@uchc.edu

Received 9 February 2014; Accepted 26 May 2014; Published 24 June 2014

Academic Editor: Mario Cannas

Copyright (C) 2014 R. James and C. T. Laurencin. This is an open access article distributed under the Creative Commons Attribution License, which permits unrestricted use, distribution, and reproduction in any medium, provided the original work is properly cited.

\begin{abstract}
Musculoskeletal tissues are critical to the normal functioning of an individual and following damage or degeneration they show extremely limited endogenous regenerative capacity. The future of regenerative medicine is the combination of advanced biomaterials, structures, and cues to re-engineer/guide stem cells to yield the desired organ cells and tissues. Tissue engineering strategies were ideally suited to repair damaged tissues; however, the substitution and regeneration of large tissue volumes and multilevel tissues such as complex organ systems integrated into a single phase require more than optimal combinations of biomaterials and biologics. We highlight bioinspired advancements leading to novel regenerative scaffolds especially for musculoskeletal tissue repair and regeneration. Tissue and organ regeneration relies on the spatial and temporal control of biophysical and biochemical cues, including soluble molecules, cell-cell contacts, cell-extracellular matrix contacts, and physical forces. Strategies that recapitulate the complexity of the local microenvironment of the tissue and the stem cell niche play a crucial role in regulating cell self-renewal and differentiation. Biomaterials and scaffolds based on biomimicry of the native tissue will enable convergence of the advances in materials science, the advances in stem cell science, and our understanding of developmental biology.
\end{abstract}

\section{Introduction}

Incidents of tissue loss or organ failure due to accidents, injuries, and disease are debilitating and have led to increased health care costs the world over [1]. Current standard of care includes organ and tissue transplantation, allografts, biofactors, and replacements composed of metals, polymers, and ceramics. However, each strategy suffers from a number of limitations. For example, autografts and allografts are often associated with limited availability and risks of immunogenicity, respectively. Tissue engineering was developed as an alternative strategy to repair and regenerate living tissues and to provide a viable tissue substitute. Bioengineer Fung first proposed the term "tissue engineering" at a 1987 meeting of the National Science Foundation [2], where it was defined as the use of isolated cells or cell substitutes, tissue-inducing substances, and cells placed on or in matrices to repair and regenerate tissue $[3,4]$. Early medical devices were physiciandriven and made using off-the-shelf materials such as Teflon, high-density polyethylene, poly(methyl methacrylate), stainless steel, polyurethane, titanium, and silicone elastomers. Over the past two decades, numerous biomaterials including synthetic and natural polymers, ceramics, and metals have been actively investigated for tissue engineering applications. Breakthroughs have been made; however, they have been limited to a very narrow portfolio of true tissue engineering products. Furthermore, many utilize tissue derivatives suggesting that a clinically successful biomaterial will closely mimic the structure, properties, and functions of the natural tissue. Formidable as it may seem, the recent advancements in material science and novel fabrication techniques show promise in developing advanced biomaterials that are capable of performing in a complex in vivo microenvironment. 
Tissue engineering is comprised of one or more of three key components: (1) three-dimensional (3D) biodegradable matrices, (2) a healthy population of harvested cells, and (3) biological factors [3]. These three reactants have been investigated in various compositions to induce repair and regeneration of several tissues and skin, nerves, and bone are the most commonly studied. In one approach, a donor organ is decellularized and the extracellular matrix (ECM) of the tissue is used as a scaffold which is then seeded with patients own cells, for example, bone marrow stromal cells (BMSCs), to create a functional substitute $[5,6]$. This approach using one's own cells mitigates the immune response that occurs with conventional transplantation procedures; however the availability of tissues that can be used for decellularization continues to be restrictive [7]. The recent advances in biomaterial synthesis and fabrication tools have made it possible to guide cells into complex 3D structures using appropriate scaffolds templates [8-10]. Increased understanding of cell-substrate communications drive efforts to develop a scaffold platform that recapitulates the ECM and thus enable control of cell migration, proliferation, and differentiation. Biodegradable scaffolds provide structural support and mechanical functionality to the damaged tissues. The scaffold undergoes degradation and presents an interconnected porous structure to accommodate cell infiltration and vascularization and promote ECM synthesis [4, 11-17]. Additionally, the delivery of stromal population contributes to the tissue formation capacity and the addition of stimulatory factors will accelerate cell differentiation and tissue remodeling.

The approaches to tissue reconstruction and regeneration have varied widely, and it is now obvious that no single approach will solve all problems; rather, each tissue and each pathologic condition require a tailored strategy to obtain optimal results. Defining and controlling the environmental niche is the key to successful tissue regeneration. Recapitulating niche conditions including structural features, biomolecule gradients, $\mathrm{pH}$, oxygen concentration, available nutrients, and mechanical forces can accelerate the regenerative process. We highlight recent advances and provide glimpses of regenerative solutions to repair and regenerate musculoskeletal tissues. The construction of diverse musculoskeletal tissues includes the combination of novel materials, architecture, stromal populations, and stimulatory factors and is achieved through the efforts of interdisciplinary scientists from developmental biology, bioengineering, biomaterials science, stem cell biology, and clinical medicine (Figure 1).

\section{Anterior Cruciate Ligament (ACL) Regeneration}

The ECM is composed of interwoven fibers made mostly of fibrillar collagen and elastin, with diameters ranging from tens to hundreds of nanometers [19]. The ECM sequesters and presents cytokines and specific binding sites for cellular adhesion. Cross communication between cells and the ECM occurring through interactions between ligands and cell surface receptors defines the microenvironment that controls

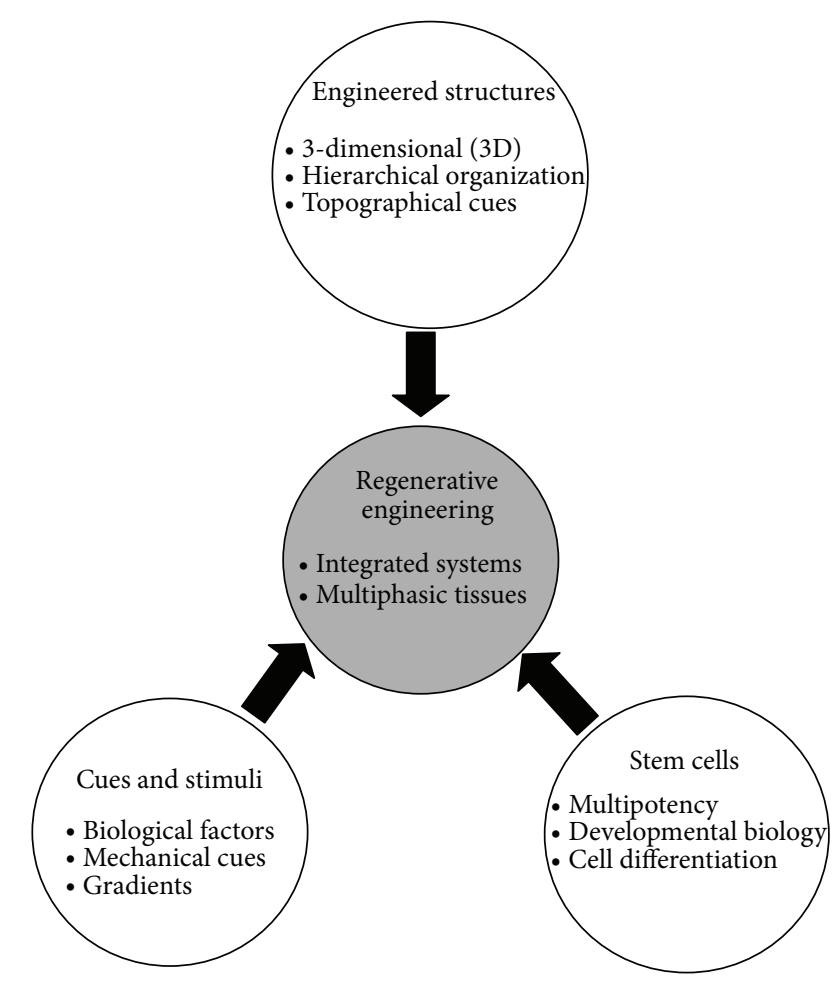

FIGURE 1: Schematics of regenerative engineering approach to create complex functional tissues and organs.

behavior and fate of the cell [20, 21]. Soft musculoskeletal tissue injuries involving the tendons and ligaments heal slowly and poorly because of limited vascularization leading to scar tissue formation and poor ECM organization and require surgical intervention $[10,19,22]$. Functional repair or regeneration of the rotator cuff, flexor tendons, and ACL remains extremely challenging [23]. Current grafts for ACL tissue replacement lack sufficient flexibility and tensile strength. Cooper et al. reported the fabrication of a biodegradable ligament device composed of biocompatible synthetic polymers based on the hierarchical complexity of natural ligament architecture [18]. Polymer fibers of diameter $15 \mu \mathrm{m}$ were woven into circular or rectangular braids of varying yarn densities and braiding patterns to achieve mechanical properties that best approximated a natural ligament (Figure 2). Several different shapes and yarn configurations were considered and evaluated through tensile testing to match the mechanical properties of the native tissue resulting in stress/strain curves that mimicked the triphasic nature of the natural ligament. These synthetic scaffolds showed an initial low modulus followed by a linear region of increased modulus ending in a plateau region, suggesting plastic deformation and ultimate failure. Synthetic ligaments were designed to be matched to the ultimate tensile strengths seen in native ligaments by varying yarn density and braid shape.

\section{Bone Tissue Engineering (BTE)}

Scaffolds for BTE applications are desired to have osteoconductive (promote osteoblast proliferation), osteoinductive 


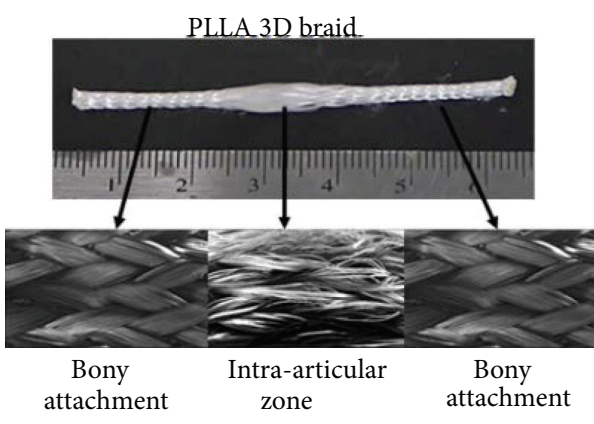

(a)

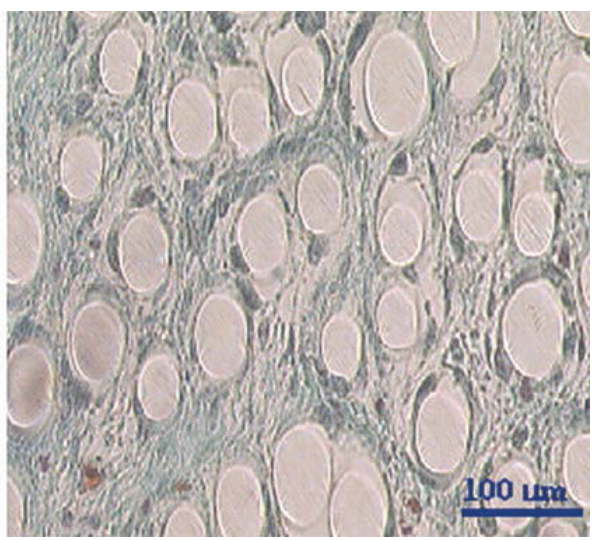

(c)

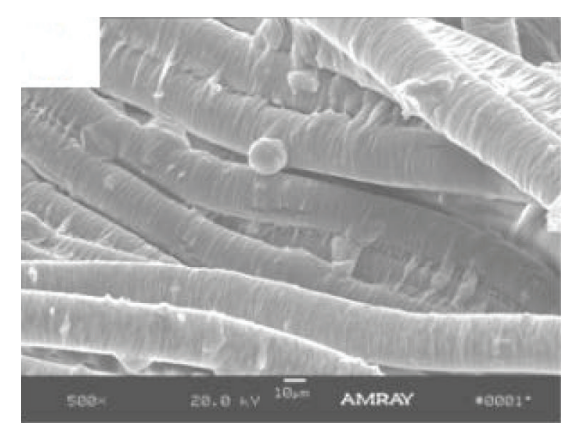

(b)

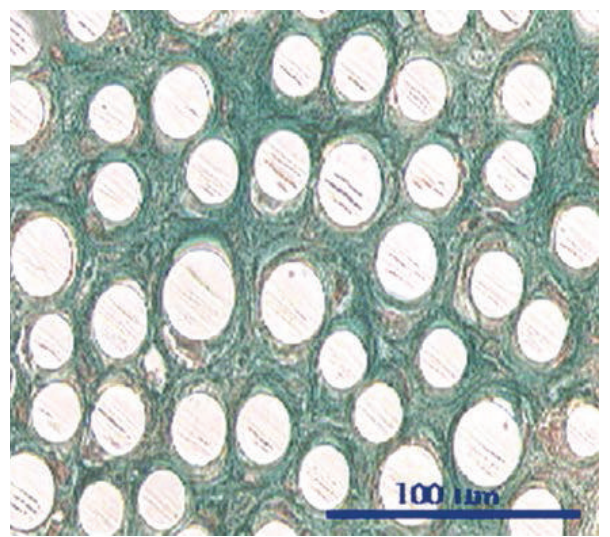

(d)

FIGURE 2: Braided ACL device composed of synthetic polyester fibers [18]. (a) Braided 3D poly-L-lactide (PLLA) ligament scaffolds showing the macrostructure of the bony attachment and intra-articular zone. (b) SEM micrograph showing rabbit ACL cells on PLLA scaffolds after 3 days of culture. In vivo assessment of the tissue-engineered ligament was done in male New Zealand white rabbits. (c) Unseeded synthetic ACL after 12 weeks of healing shows moderate collagen infiltration between fiber bundles; and (d) seeded synthetic ACL after 12 weeks of healing shows enhanced tissue infiltration. "Reprinted from Proceedings of the National Academy of Sciences of the United States of America, 104 [8], Cooper et al. Biomimetic tissue-engineered anterior cruciate ligament replacement, 3049-54, 2007, with permission from The National Academy of Sciences of the USA."

(promote osteoblastic differentiation of progenitor cells), and osteointegrative (form an intimate contact and anchor into the surrounding bone) properties to promote bone regeneration. The scaffold is designed to maintain the structure of the defect and restore bone function and ideally should satisfy a number of design criteria to achieve properties comparable to autologous grafts: the scaffold should be (1) biocompatible so that it is integrated with host tissues without any immune response; (2) mechanically competent in order to tolerate the local mechanical forces; this is necessary to protect tissues and transmit the compressive and tensile cues to the regenerative cells; (3) biodegradable with nontoxic degradation products that can be metabolized and excreted by the body; (4) osteoconductive with porous structure to allow cell infiltration, proliferation, neovascularization, and nutrient transport: (5) lastly, scaffolds should be able to integrate with the surrounding osseous tissue through the formation of bone bonding.

Borden et al. reported a BTE scaffold using heat sintering technique to fabricate sintered microsphere matrices having sufficient porosity for cellular migration and movement of fluids across the scaffolds $[24,25]$. These $3 \mathrm{D}$ heat sintered scaffolds were made using polymeric biomaterials such as poly(lactide-co-glycolide) (PLAGA) [24, 25]. By orderly packing and heating of PLAGA microspheres in a predefined mold, neighboring individual microspheres bind together resulting in scaffolds closely mimicking the mechanical properties of human trabecular bone. The pore structure is a negative template of trabecular bone in structure and volume, and the new bone would occupy the pores while the microsphere matrix slowly degraded leaving voids that will form the pore structure of newly formed trabecular bone. These scaffolds have approximately $30 \%$ pore volume with median pore sizes ranging from $100-300 \mu \mathrm{m}$ thus allowing bone cells and tissue ingrowth. When the polymer scaffold completely degrades, the regenerated bone tissue possesses approximately $70 \%$ void volume resembling that of human trabecular bone. These $3 \mathrm{D}$ porous scaffolds can act as a delivery vehicle for bioactive molecules, growth factors, and cells to the defect site for tissue morphogenesis and defect healing. We modified this technique to fabricate 3D sintered chitosan microsphere scaffolds using both solvent and heat sintering [26-28]. Chitosan, due to its many advantages as a natural biomaterial, has been of interest for various 


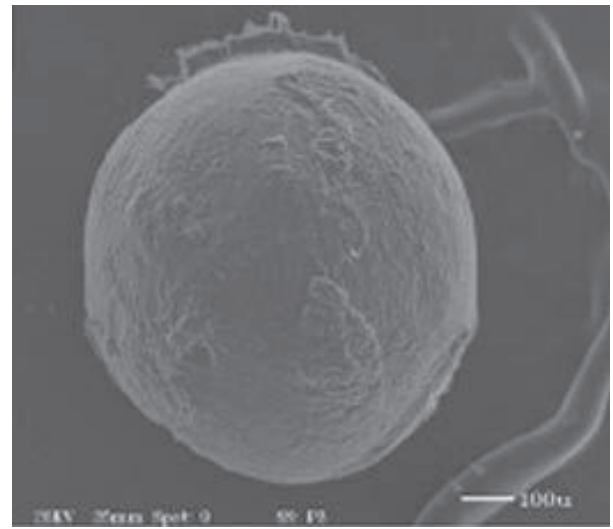

(a)

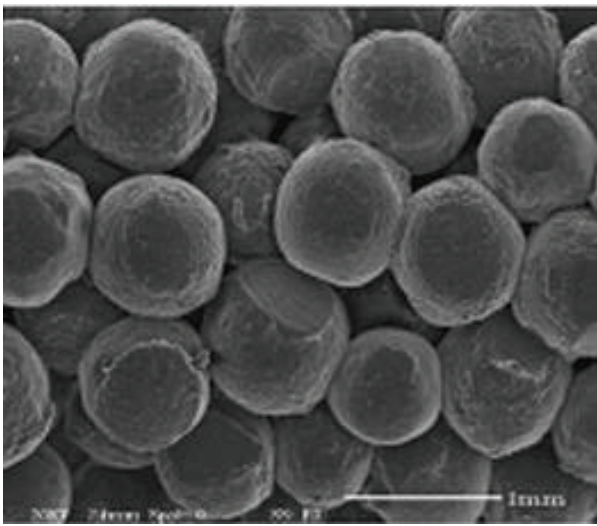

(c)

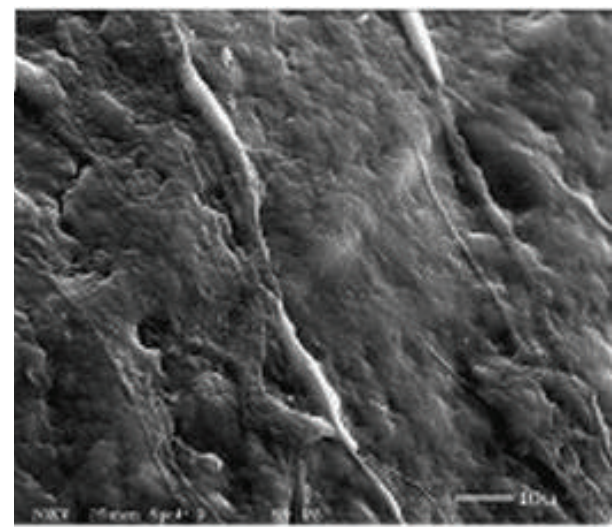

(e)

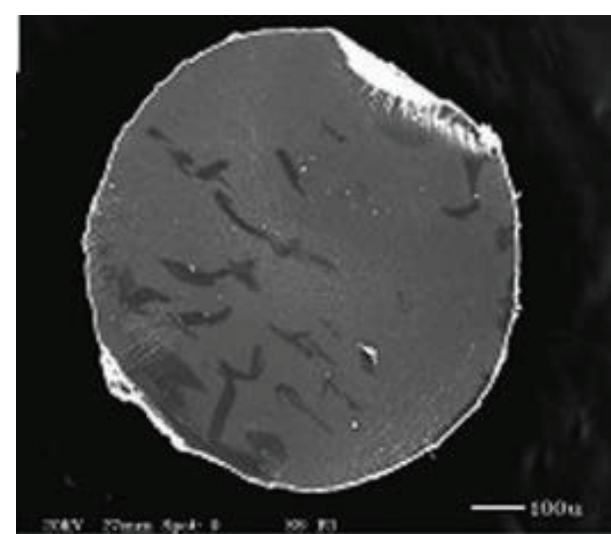

(b)

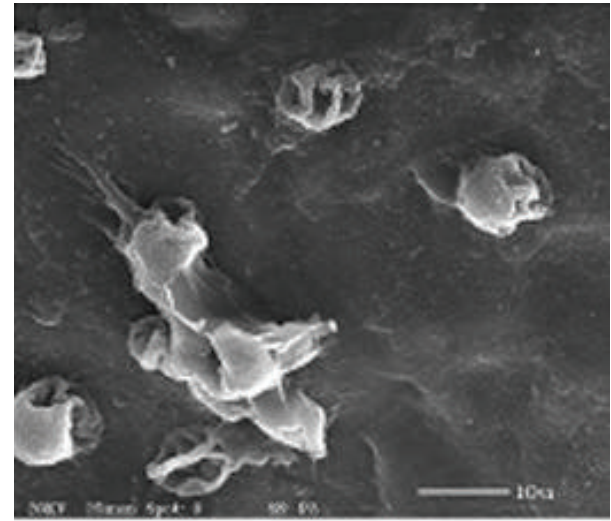

(d)

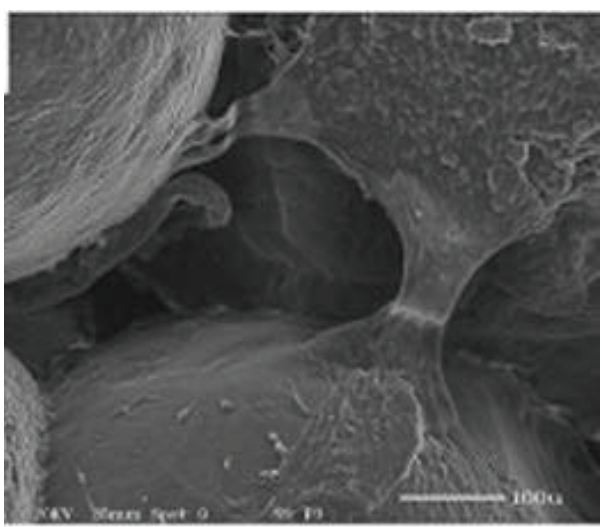

(f)

Figure 3: (a) A chitosan microsphere formed by ionotropic gelation; (b) cross-sectional view of a chitosan microsphere; (c) a 3D chitosan scaffold fabricated by solvent/heat sintering microspheres; (d)-(f) MC3T3-E1 osteoblast-like cell proliferation on the 3D chitosan scaffold at days 4,7 , and 14 , respectively. Cells initially attached and proliferated on the microsphere surfaces and migrated to the neighboring microspheres.

applications such as lab-on-a-chip devices, patterned structures for cellular engineering, and microstructured scaffolds for tissue engineering $[29,30]$. Chitosan microspheres prepared by ionotropic gelation were packed and heattreated to obtain a 3D chitosan microsphere scaffold. Bonding between adjacent chitosan microspheres contributed to the high initial mechanical properties of the scaffold. The chitosan scaffolds were biocompatible and supported the attachment and proliferation of MC3T3-E1 osteoblast cells as shown in Figure 3 [31]. Composite microsphere scaffolds prepared from chitosan/PLAGA microspheres [32] presented a rough surface morphology with chitosan microparticles evenly distributed on the microsphere surface (Figure 4(a)). In addition, the sintered microsphere scaffolds exhibited excellent interconnected porous structure (Figure 4(b)) and appropriate mechanical properties suitable for load-bearing 

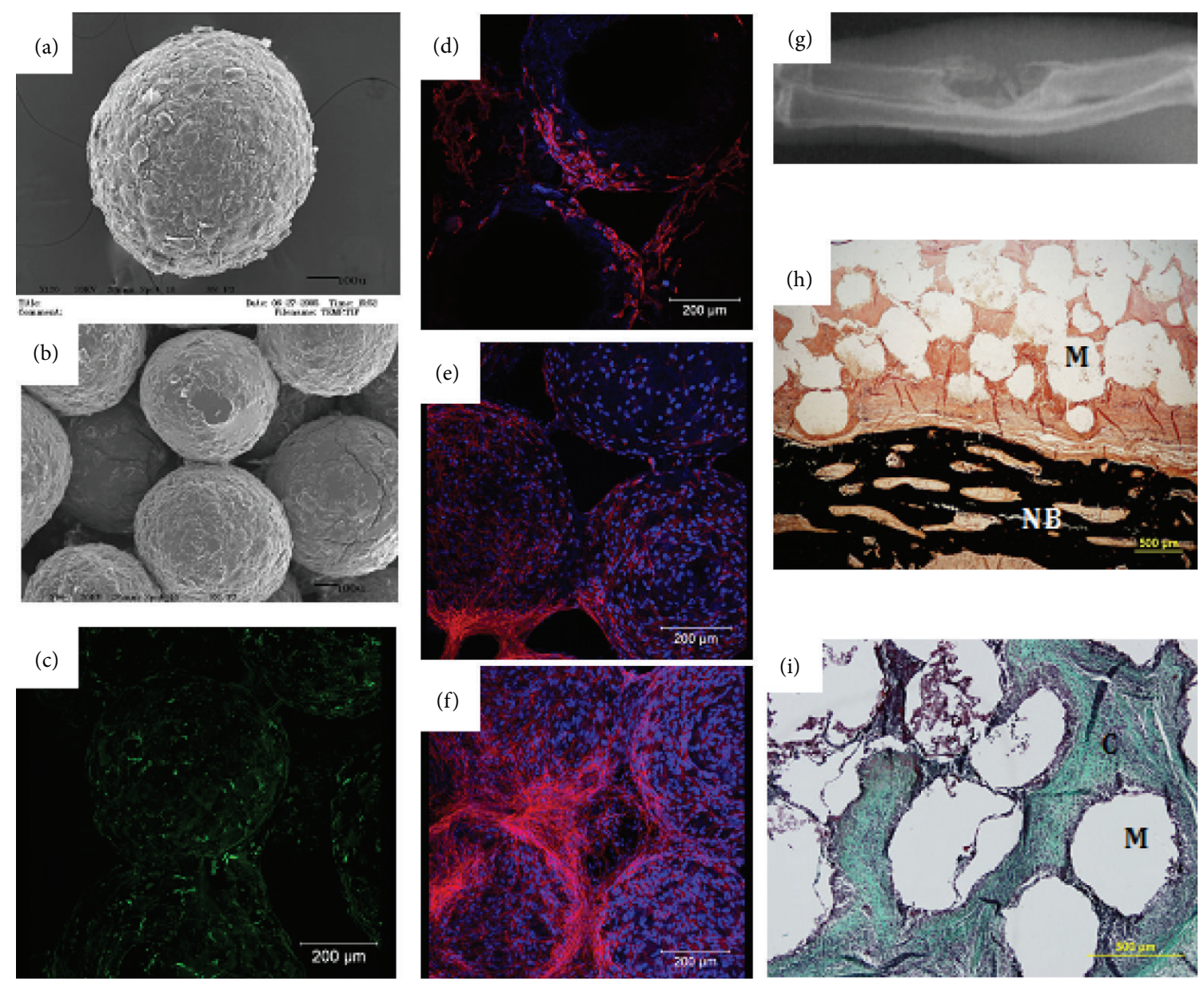

Figure 4: (a) A chitosan/PLAGA composite microsphere; (b) a 3D chitosan/PLAGA scaffold fabricated by heat sintering; "reprinted from Biomaterials, 27/28, Jiang et al. in vitro evaluation of chitosan/poly(lactic acid-glycolic acid) sintered microsphere scaffolds for bone tissue engineering, pg. 4894, 2006, with permission from Elsevier." (c) Chitosan/PLAGA scaffold immobilized with heparin as evidenced by the green fluorescence; (d)-(f) MC3T3-E1 osteoblast-like cell proliferation at days 4, 7, and 11 on the heparinized chitosan/PLAGA scaffolds as illustrated by dual staining of cell nuclei (blue) and cytoskeletal protein actin (red); "reprinted from Journal of Biomedical Materials Research, 93A/3, Jiang et al. functionalization of chitosan/poly(lactic acid-glycolic acid) sintered microsphere scaffolds via surface heparinization for bone tissue engineering, pg. 1193, 2009, with permission from John Wiley and Sons." (g) A radiograph showing new bone formation bridging the critical-sized defect at 12 weeks after operation using chitosan/PLAGA scaffolds loaded with heparin and bone morphogenetic protein-2 using a rabbit ulnar model; (h) Von Kossa staining of implanted scaffold showing new bone formation adjacent to the scaffold (M: microsphere, NB: new bone); (i) trichrome staining showing dense connective tissue formation in the void space among microspheres (CT: connective tissue). "Reprinted from Acta Biomaterialia, 6/9, Jiang et al., Chitosan-poly(lactide-co-glycolide) microsphere-based scaffolds for bone tissue engineering: in vitro degradation and in vivo bone regeneration studies, pg. 3457, 2010, with permission from Elsevier."

bone tissue regeneration. The composite chitosan/PLAGA scaffolds served as good substrate materials for osteoblast cell proliferation. In addition, the presence of chitosan led to enhanced cell differentiation and phenotype expression.

The composite chitosan/PLAGA scaffolds were surface functionalized with the biomolecule heparin via ionic interaction between oppositely charged chitosan and heparin molecules (Figure 4(c)) [33]. The heparin modified chitosan/PLAGA scaffolds supported osteoblast cell ingrowth into the porous scaffold in vitro (Figures 4(d)-4(f)). A rabbit ulnar critical sized bone defect model was used to evaluate the ability of the bioactive scaffolds to regenerate bone (Figure 4(g)) [17]. New bone formation on the edge of the scaffolds along with extensive connective tissue formation within the pores of the scaffolds was observed (Figures $4(\mathrm{~h})$ and 4(i)).

Scaffolds derived from polymers of natural origin, namely, polysaccharides and proteins, are known to be bioactive and highly biocompatible supporting cell attachment, proliferation, and differentiation in vitro and in vivo [34]. Aravamudhan et al. reported that micro-nano structured biomimetic scaffolds composed of cellulose and fabricated using solvent/nonsolvent sintering technique (Figure 5) and surface functionalized with self-assembled collagen nanofibers (Figure 6) exhibits superior mechanical properties suited for BTE applications [35-37]. Scaffold mechanical and pore properties are inversely proportional and hence a balance between these two important parameters needs to 


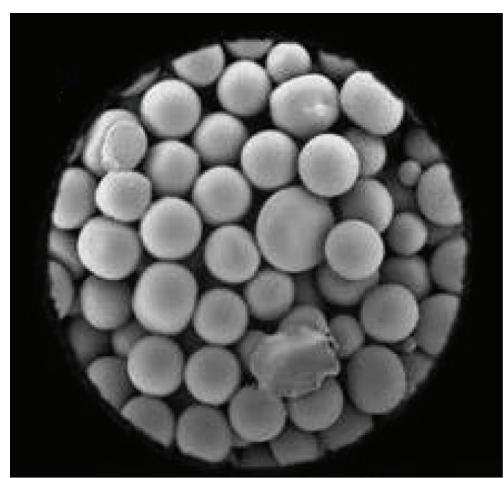

(a)

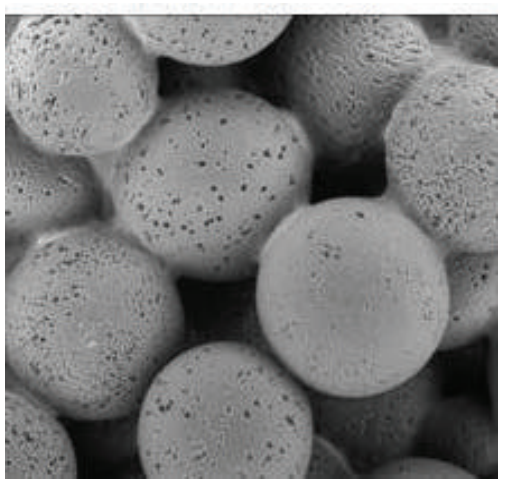

(d)

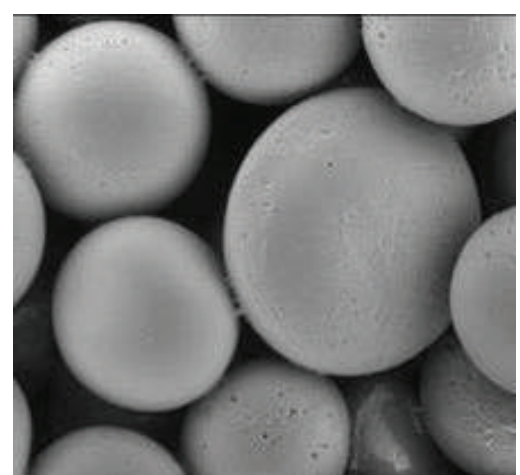

(b)

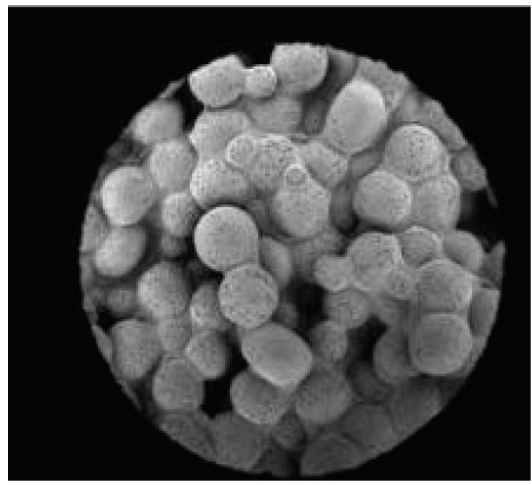

(e)

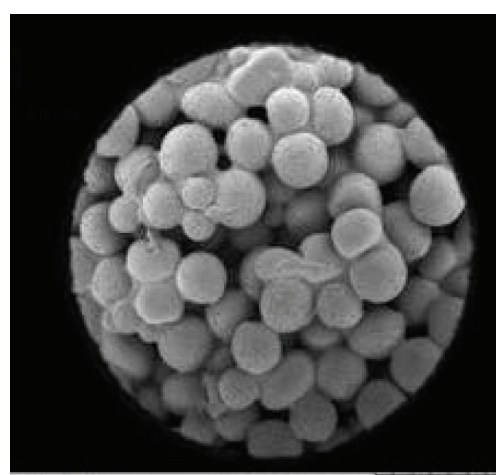

(c)

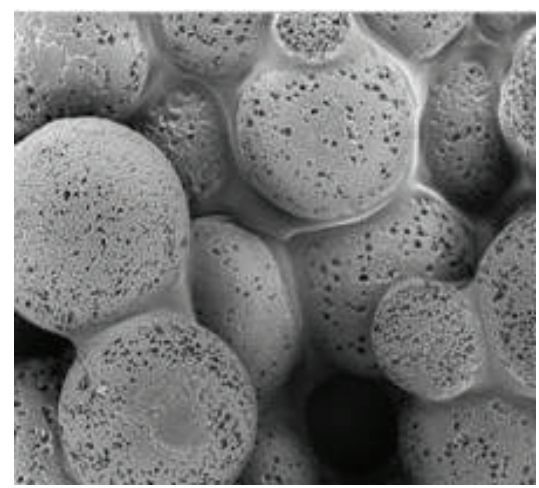

(f)

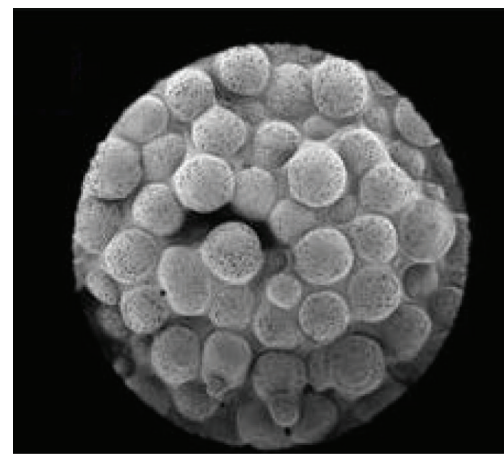

(g)

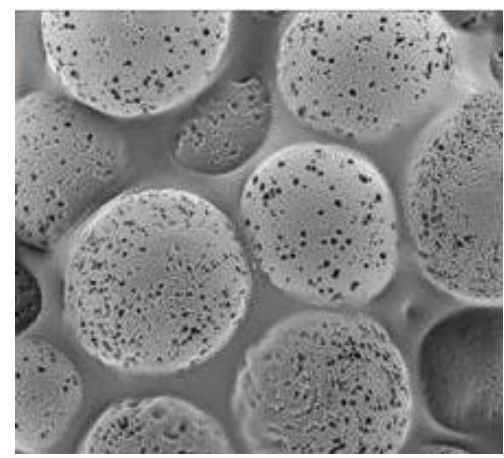

(h)

FIGURE 5: Effect of solvent/nonsolvent composition on the morphology of the resulting sintered microsphere scaffolds. Acetone is a solvent for CA while cyclohexane is a nonsolvent. Acetone : cyclohexane ratio was varied 1:0,2:1, 3:1, 4:1, and 5:1. The 30x and 100x SEM images of CA scaffolds with varying acetone/cyclohexane sintering solution concentrations: (a) 2:130x, (b) 2:1 100x (c) 3:130x, (d) 3:1 100x, (e) 4:130x, (f) 4:1100x, (g) 5:130x, and (h) 5:1100x. Higher solvent compositions led to greater bonding between adjacent microspheres. "Republished with permission of American Scientific Publishers (ASP), from Cellulose and collagen derived micronanostructured scaffolds for bone tissue engineering, Aravamudhan et al., 9 [4], 2013; permission conveyed through Copyright Clearance Center, Inc.”

be optimized [24]. Microspheres in the diameter range of $300-425,600-710$, and $710-800 \mu \mathrm{m}$ were fabricated into 3D porous structures via a solvent/nonsolvent sintering technique [35]. These microsphere scaffolds fabricated from natural polymers show compressive mechanical properties in the midrange of human trabecular bone and functionalization with collagen nanofibers did not compromise mechanical and pore properties. Improved human osteoblast adhesion, proliferation, alkaline phosphatase expression, and mineralized matrix synthesis on these scaffolds were evidenced as compared to that on control tissue culture plastic and PLAGA scaffolds confirming their potential for bone regeneration.

\section{Small Molecule Modulated Tissue Regeneration}

In addition to the architecture and inherent properties of a polymer based scaffold, the use of biochemical cues to stimulate bone formation is an established approach to treating musculoskeletal diseases and trauma. Urist and coworkers 


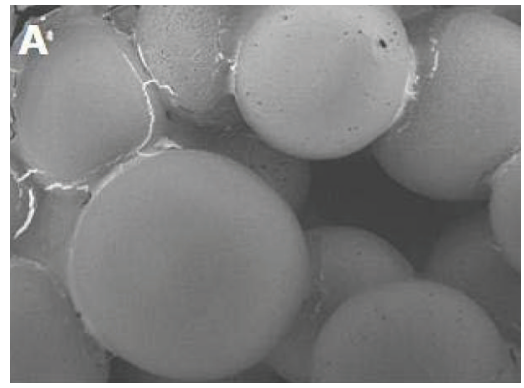

(a)

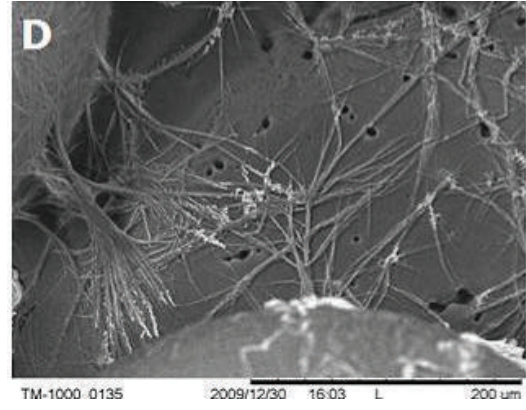

(d)

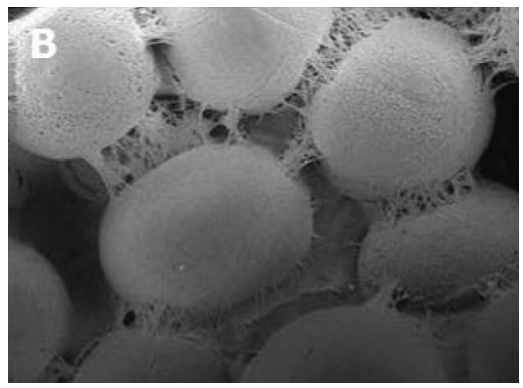

(b)

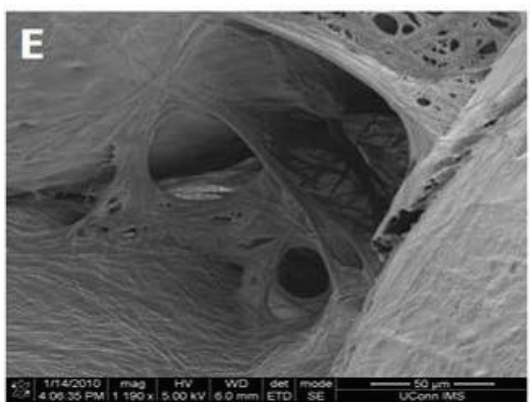

(e)

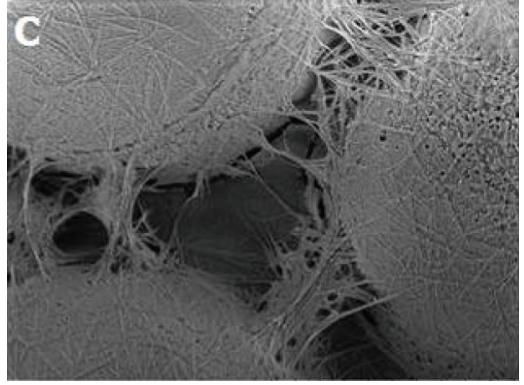

(c)

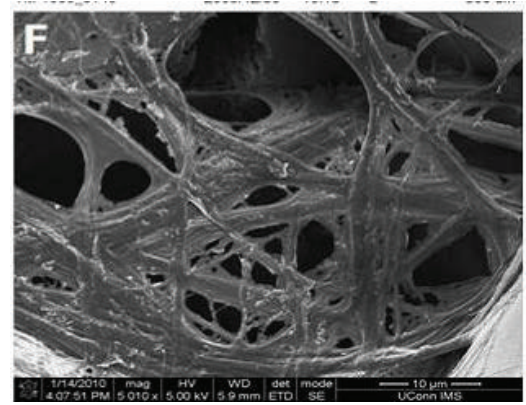

(f)

FIGURE 6: SEM micrographs ((b) and (c)) illustrate the top view of CA-micronanostructured scaffold surface morphology where A is a control CA microstructured scaffold. Micrographs (a)-(d) were recorded on an environmental SEM without applying Au-Pd coating. Representative micrographs (d)-(f) illustrate the deep interior surface morphology of the composite scaffolds taken on several randomly broken pieces of the different scaffolds. Micrographs (e) and (f) at higher magnifications were imaged after coating with Au-Pd using a FESEM. Preferred Collagen nanofiber $(140 \pm 40 \mathrm{~nm})$ assembly on the microsphere surface may be attributed to polysaccharide hydrophilic nature as well as slower water evaporation during scaffold drying process. Collagen coating was uniform throughout the scaffold 3D architecture with enhanced surface area as compared to neat CA scaffolds. "Republished with permission of American Scientific Publishers (ASP), from Cellulose and collagen derived micronanostructured scaffolds for bone tissue engineering, Aravamudhan et al., 9 [4], 2013; permission conveyed through Copyright Clearance Center, Inc."

discovered the osteoinductive property within decalcified bone and named the protein bone morphogenetic protein (BMP) [38-40]. Bone morphogenetic proteins (BMPs) have received clearance from US FDA for specific clinical applications [41, 42]. BMPs are produced by Escherichia coli using recombinant DNA technology and this method for recombinant protein production and purification is very expensive, and furthermore the protein produced by E. coli is not glycosylated as found in the body and thus may present reduced stability and biological activity $[43,44]$. Drug delivery approaches use harsh organic solvents, crossinglinking reagents, and/or high temperatures which may lead to the denaturation or deactivation of recombinant proteins $[43,45]$. Small molecules $(<1000 \mathrm{Da})$ are significantly more stable and have low or no immunogenicity which enable them to be attractive alternatives for osteoinductive factors. Small molecules are inexpensive to manufacture and do not require a specific structural conformation to present bioactivity and thus are able to overcome the drawbacks associated with growth factors. Recently, Lo et al. have shown that stimulation of protein kinase A (PKA) signaling pathway by continuous administration of 6-Bnz-cAMP which is a PKA-specific cyclic adenosine monophosphate (cAMP) analog promoted in vitro osteogenesis in MC3T3-E1 and hMSCs [46]. The cAMP signaling pathway is required for integrin-mediated cell adhesion in a number of cell types $[47,48]$. cAMP-dependent PKA is a unique sensor for cAMP resulting in the phosphorylation of a large variety of downstream target proteins and thereby regulates multiple cellular events including cell-cell and cell-substrate adhesion $[49,50]$. The early studies identified that the 6-BnzcAMP small molecule enhanced osteoblastic cell adhesion on biodegradable biomaterials. Furthermore, it was identified that cAMP analogs can modulate cell differentiation and mineralization (Figure 7). In vitro studies show that 6-BnzcAMP upregulates expression of several osteogenic marker proteins from early to late stages of differentiation, which ultimately leads to calcium precipitation in MC3T3-E1 cells via the PKA signaling cascade. These studies indicate that small molecule 6-Bnz-cAMP may potentially function as an alternative growth factor for bone repair and regeneration.

\section{Articular Cartilage Tissue Regeneration}

Cartilage is the smooth white tissue that covers the ends of bones enabling successful load transmission and mobility within the joints. It can be damaged by injury or normal wear and tear, occurring in the form of localized defects or primary osteoarthritis leading to significant pain and loss of 


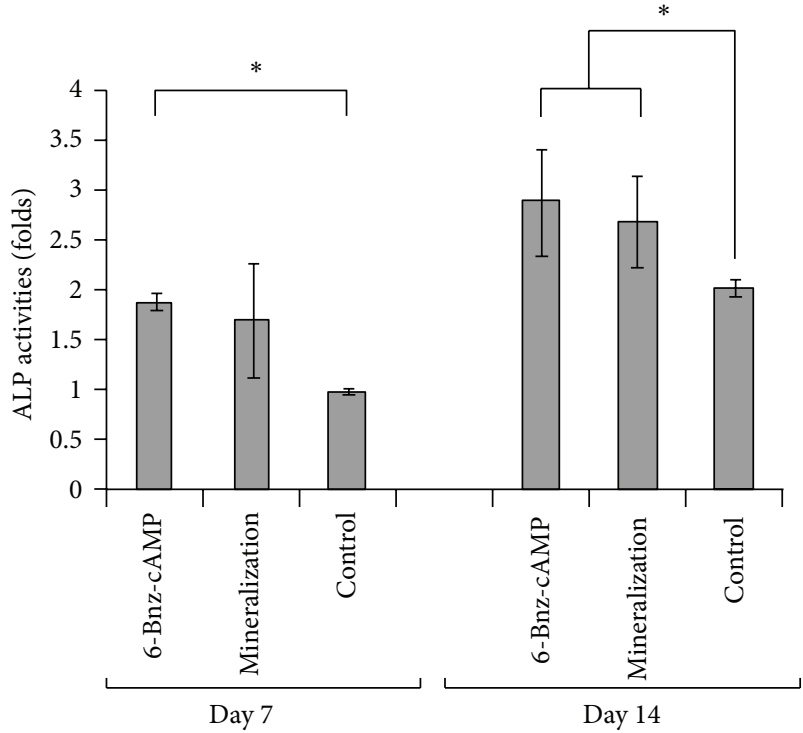

(a)

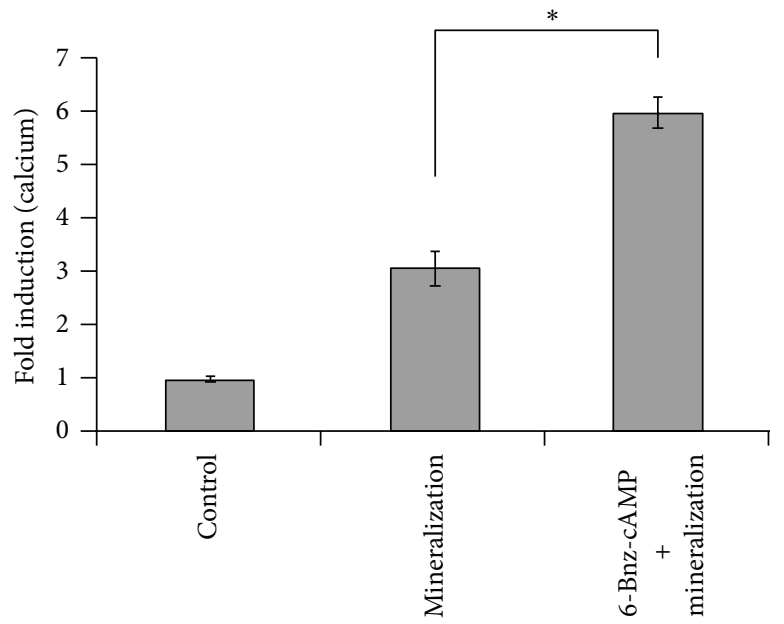

(b)

FIgURE 7: (a) 6-Bnz-cAMP increases ALP activity. ALP activities of MC3T3-E1 cells were induced by 6-Bnz-cAMP at day 7 and further increased at day 14. (b) Osteoblast-like MC3T3-E1 cells cultured in mineralization medium supplemented with 6-Bnz-cAMP further enhanced calcium deposition when compared to cells cultured in the mineralization medium alone at day 21. "The small molecule PKA-specific cyclic AMP analogue as an inducer of osteoblast-like cells differentiation and mineralization/Kevin W.-H. Lo et al./Journal of Tissue Engineering and Regenerative Medicine and 6/1. Copyright (c) 2011 John Wiley \& Sons, Ltd.”

mobility [51]. Unfortunately, cartilage has a limited capacity for self-repair, due to its inherent avascular noninnervated nature, low cell density, and lack of normal tissue repairassociated humoral factors, leaving only symptomatic treatment strategies such as nonsteroidal anti-inflammatory drugs or surgery for those with severe symptoms [52]. Current surgical approaches include various forms of abrasion chondroplasty, microfracture, transplantation of osteochondral plugs, or the use of cultured autologous chondrocytes [53]. Each of these treatment strategies has shown some temporary benefit in improving patient symptoms: however, they do not delay or halt the progression towards end stage degeneration. These early osteochondral lesions will ultimately require total joint replacement as the disease process advances. The optimal osteochondral graft for cartilage tissue engineering repairs the damaged cartilage and underlying bone allowing for subchondral repair and the formation of neocartilage tissue. It is challenging to engineer a scaffold that supports the regeneration of bone and cartilage tissue at the joint defect, mainly due to the lack of adequate mechanical properties and cell support for bone and cartilage phenotype. The tissueengineered graft should produce tissue that is qualitatively similar to the native tissues at the site of the defect and incorporates quickly and fully into the host joint.

We have reported the fabrication of a novel osteochondral construct composed of acid demineralized bone-derived material (bone matrix gelatin; BMG) [54]. Following 6-week in vitro culture of the construct with primary chondrocytes, a $1.3 \mathrm{~mm}$ thick hyaline-like cartilage cap was produced on the BMG scaffolds which exhibited histological similarity to native articular cartilage. Macroscopically, the neocartilage matrix was attached to the BMG scaffold and did not separate. Histological staining of the tissue-engineered constructs revealed chondrocytes located in lacunate, separated from each other by interterritorial extracellular matrix (Figure 8). We observed within the neocartilage different zonal-like layers (tangential layer, transitional layer, and radial layer). A layer of small and flattened chondrocytes was observed in the most superficial part of the construct parallel to the surface of BMG scaffold. Underneath this layer, in the midportion, the chondrocytes appeared slightly larger and rounded and was evident singly and in isogenous groups. Closer to the BMG scaffold, the chondrocytes formed radial columns, that is, cellular stacks oriented perpendicular to the BMG scaffold, and adjacent to the scaffold the cells were flattened. Safranin-O staining demonstrated an extracellular matrix composed mainly of glycosaminoglycans. Clinically the regeneration of both chondral and subchondral components of an osteochondral defect is desirable. This in vitro study demonstrated the formation of a cartilage cap with cells present in zonal layers similar to the native joint surface. This novel engineered-scaffold exhibits potential to modulate both chondrogenesis and osteogenesis thus appears promising for the repair of small, osteochondral defects at weight-bearing joints. Other studies have demonstrated the fabrication of tunable hydrogel networks containing ECM molecules such as chondroitin sulfate (CS), hyaluronic acid (HA), and heparan sulfate (HS) to modulate chondrogenesis using a combination of biochemical and mechanical (matrix stiffness) cues $[55,56]$. 

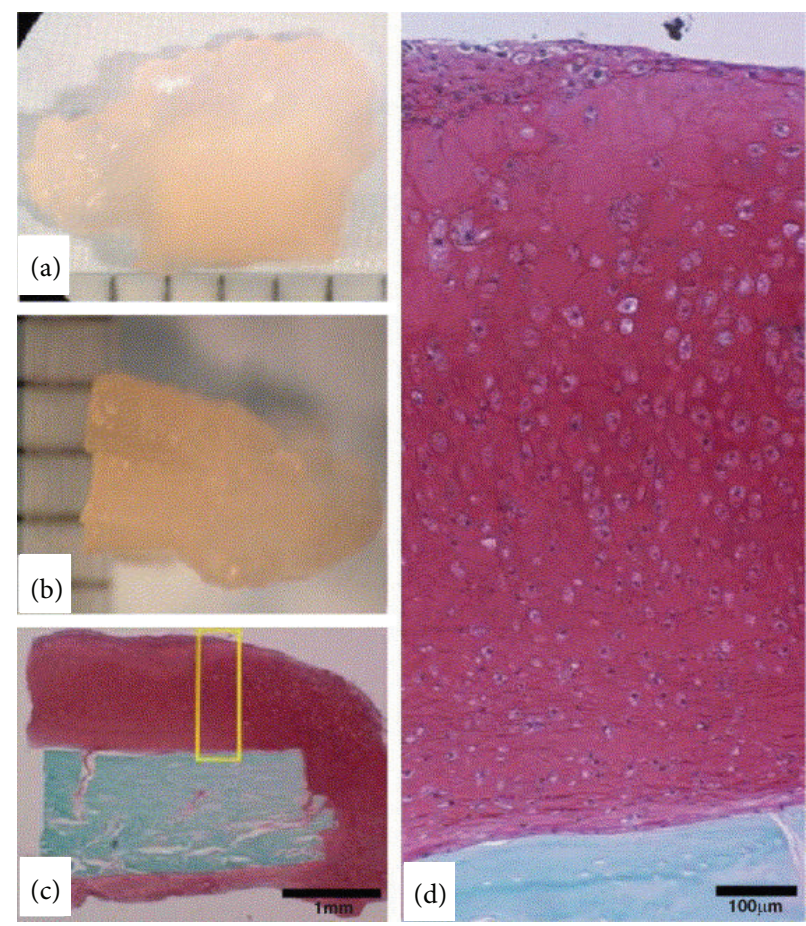

FIGURE 8: Gross morphology (a,b) and histology (c, d) of in vitro osteochondral construct after 6 weeks in culture. (a) Construct photographed lying flat; (b) construct photographed on the side. The scale shown is in millimeters; (c) Safranin-O staining of construct, meter bar = $1 \mathrm{~mm}$; (d) enlarged view, scale bar $=100 \mu \mathrm{m}$. "Reprinted from Biomaterials, 27/11, Li et al. Demineralized bone matrix gelatin as scaffold for osteochondral tissue engineering, pg. 2426, 2006, with permission from Elsevier."

\section{Future Outlook}

The challenge for the future is the simultaneous formation of multiple types of tissues and the functional assembly of these tissues into complex organ systems. The grand challenge in musculoskeletal tissues is to achieve complete limb regeneration: like for example, in a newt or salamander, an injured or severed limb will be completely regenerated within a period of 10 weeks [21]. A continuous multiscale tissue organization is rarely reestablished following surgical repair and is even more difficult to restore functionality similar to the native tissue system/organ affecting long term clinical outcomes and stability of the regenerated tissue. A multilevel scaffold presenting a gradient of guidance cues such as structural, mechanical, and stimulatory molecules in a continuous substrate will be instrumental in the development of complex musculoskeletal tissue systems. Laurencin and Khan defined "regenerative engineering" as taking tissue engineering a step further by integrating it with advanced materials science, stem cell science, and areas of developmental biology [57]. Tissue engineering involves interdisciplinary teams from the fields of engineering, science, and medicine, and we visualize regenerative engineering as a "convergence" [58] of tissue engineering with nanotechnology, stem cells, and developmental biology [21]. This new frontier, enabling the reconstruction of complex tissues and whole organs, requires the combination of top-down engineering approaches with bottom-up strategies that integrate materials science and tissue engineering with stem cell and developmental biology [57]. The emergence of regenerative strategies represents both technical advances as well as an evolution of patient preferences. Conventional treatments such as total knee replacement, total shoulder replacement, urostomy bag, and pacemaker may be replaced by innovative alternatives such as restorable meniscal matrices, regenerative rotator cuff scaffolds, functional bladder, and pacemaker cells, respectively. Regenerative engineering has elements of tissue engineering but is distinct in recognizing the robust new technologies that have come to the fore in the design of solutions for the regeneration of tissues.

A key element is to utilize biomaterials as guides for tissue development, where we will engineer substrates that, through topographical and physicochemical means, will influence the differentiation of multipotent cell types $[59,60]$. Scientists must develop an excellent understanding of cell behavior, and signaling mechanisms especially of cell-material interactions and how they modulate cellular events. The complexity within the native tissues and organs necessitates the development of biomimetic scaffold platforms that will precisely control cellular events especially in regenerating various tissues in a continuous substrate. The focus needs to be on identifying the unique parameters that trigger specific signaling events and improve understanding of the mechanistic pathways that drive development of tissues. Recapitulating the stem cell microenvironment using 3D scaffolds will maintain the stem cell population and guidance provided by incorporated cues will direct the stem cells to the desired lineages within the multiscale tissue structures. A single stem cell source combined with a multiscale scaffold 
eliminates the need for matching organ donors, minimizes the risk of immune rejection, and reduces the waiting period. The regenerative engineering toolbox that we and others are developing will be further enhanced over the next few decades leading to new strategies and mergers of disparate technologies. We will move beyond addressing individual tissue repair to complex tissue systems such as joint complexes, limbs, and other organ systems by capitalizing on the concept of convergence by incorporating advanced materials science, stem cell science, and developmental biology.

\section{Disclosure}

Cato T. Laurencin discloses a financial interest (stock and consulting agreement) in Soft Tissue Regeneration Incorporated and Natural Polymer Devices Incorporated. Cato T. Laurencin also discloses receiving royalties from Globus Medical Inc.

\section{Conflict of Interests}

Roshan James declares that there is no conflict of interests regarding the publication of this paper.

\section{Acknowledgments}

The authors gratefully acknowledge funding from the Raymond and Beverly Sackler Center for Biomedical, Biological, Physical and Engineering Sciences, NSF AIR 1311907 and NSF EFRI 1332329. Cato T. Laurencin, M.D., Ph.D., is the recipient of Presidential Faculty Fellow Award from the National Science Foundation.

\section{References}

[1] J. P. Vacanti and R. Langer, "Tissue engineering: the design and fabrication of living replacement devices for surgical reconstruction and transplantation," The Lancet, vol. 354, supplement 1, pp. SI32-SI34, 1999.

[2] Y. Fung, "A proposal to the National science Foundation for An Engineering Research Centre at USCD," Center for the Engineering of Living Tissues UCSD. 2001; 865023.

[3] R. Langer and J. P. Vacanti, “Tissue engineering," Science, vol. 260, no. 5110, pp. 920-926, 1993.

[4] C. T. Laurencin, A. M. A. Ambrosio, M. D. Borden, and J. A. Cooper Jr., "Tissue engineering: orthopedic applications," Annual Review of Biomedical Engineering, vol. 1, no. 1, pp. 1946, 1999.

[5] T. H. Petersen, E. A. Calle, L. Zhao et al., "Tissue-engineered lungs for in vivo implantation," Science, vol. 329, no. 5991, pp. 538-541, 2010.

[6] H. C. Ott, T. S. Matthiesen, S.-K. Goh et al., "Perfusiondecellularized matrix: using nature's platform to engineer a bioartificial heart," Nature Medicine, vol. 14, no. 2, pp. 213-221, 2008.

[7] S. F. Badylak, D. Taylor, and K. Uygun, "Whole-organ tissue engineering: decellularization and recellularization of threedimensional matrix scaffolds," Annual Review of Biomedical Engineering, vol. 13, pp. 27-53, 2011.
[8] T. Dvir, B. P. Timko, D. S. Kohane, and R. Langer, "Nanotechnological strategies for engineering complex tissues," Nature Nanotechnology, vol. 6, no. 1, pp. 13-22, 2011.

[9] C. M. Kelleher and J. P. Vacanti, "Engineering extracellular matrix through nanotechnology," Journal of the Royal Society Interface, vol. 7, supplement 6, pp. S717-S729, 2010.

[10] R. James, U. S. Toti, C. T. Laurencin, and S. G. Kumbar, "Electrospun nanofibrous scaffolds for engineering soft connective tissues," Methods in Molecular Biology, vol. 726, pp. 243-258, 2011.

[11] R. Langer, “Tissue engineering," Molecular Therapy, vol. 1, no. 1, pp. 12-15, 2000.

[12] M. Deng, L. S. Nair, S. P. Nukavarapu et al., "In situ porous structures: a unique polymer erosion mechanism in biodegradable dipeptide-based polyphosphazene and polyester blends producing matrices for regenerative engineering," Advanced Functional Materials, vol. 20, no. 17, pp. 2794-2806, 2010.

[13] M. Deng, L. S. Nair, S. P. Nukavarapu et al., "Biomimetic, bioactive etheric polyphosphazenepoly(lactide-co-glycolide) blends for bone tissue engineering," Journal of Biomedical Materials Research A, vol. 92, no. 1, pp. 114-125, 2010.

[14] M. Deng, S. G. Kumbar, Y. Wan, U. S. Toti, H. R. Allcock, and C. T. Laurencin, "Polyphosphazene polymers for tissue engineering: an analysis of material synthesis, characterization and applications," Soft Matter, vol. 6, no. 14, pp. 3119-3132, 2010.

[15] M. Deng, L. S. Nair, S. P. Nukavarapu et al., "Dipeptidebased polyphosphazene and polyester blends for bone tissue engineering," Biomaterials, vol. 31, no. 18, pp. 4898-4908, 2010.

[16] E. Jabbarzadeh, T. Starnes, Y. M. Khan et al., "Induction of angiogenesis in tissue-engineered scaffolds designed for bone repair: a combined gene therapy-cell transplantation approach," Proceedings of the National Academy of Sciences of the United States of America, vol. 105, no. 21, pp. 11099-11104, 2008.

[17] T. Jiang, S. P. Nukavarapu, M. Deng et al., "Chitosanpoly(lactide-co-glycolide) microsphere-based scaffolds for bone tissue engineering: in vitro degradation and in vivo bone regeneration studies," Acta Biomaterialia, vol. 6, no. 9, pp. 3457-3470, 2010.

[18] J. A. Cooper Jr., J. S. Sahota, W. J. Gorum II, J. Carter, S. B. Doty, and C. T. Laurencin, "Biomimetic tissue-engineered anterior cruciate ligament replacement," Proceedings of the National Academy of Sciences of the United States of America, vol. 104, no. 9, pp. 3049-3054, 2007.

[19] R. James, G. Kesturu, G. Balian, and A. B. Chhabra, “Tendon: biology, biomechanics, repair, growth factors, and evolving treatment options," Journal of Hand Surgery, vol. 33, no. 1, pp. 102-112, 2008.

[20] R. James, M. Deng, C. T. Laurencin, and S. G. Kumbar, "Nanocomposites and bone regeneration," Frontiers of Materials Science, vol. 5, no. 4, pp. 342-357, 2011.

[21] W. Reichert, B. D. Ratner, J. Anderson et al., "2010 panel on the biomaterials grand challenges," Journal of Biomedical Materials Research A, vol. 96, no. 2, pp. 275-287, 2011.

[22] S. G. Kumbar, R. James, S. P. Nukavarapu, and C. T. Laurencin, "Electrospun nanofiber scaffolds: engineering soft tissues," Biomedical Materials, vol. 3, no. 3, Article ID 034002, 2008.

[23] M. V. Hogan, J. N. Irvine Jr., R. Ma, R. James, S. F. ElAmin, and Q. Cui, "Recent patents in bone graft substitute for bone, tendon, and ligament reconstruction," Recent Patents on Biomedical Engineering, vol. 5, no. 2, pp. 142-147, 2012. 
[24] M. Borden, S. F. El-Amin, M. Attawia, and C. T. Laurencin, "Structural and human cellular assessment of a novel microsphere-based tissue engineered scaffold for bone repair," Biomaterials, vol. 24, no. 4, pp. 597-609, 2003.

[25] M. Borden, M. Attawia, Y. Khan, and C. T. Laurencin, “Tissue engineered microsphere-based matrices for bone repair: design and evaluation," Biomaterials, vol. 23, no. 2, pp. 551-559, 2002.

[26] T. Jiang, C. M. Pilane, and C. T. Laurencin, "Fabrication of novel porous chitosan matrices as scaffolds for bone tissue engineering," in Nanoscale Materials Science in Biology and Medicine, C. Laurencin and E. A. Botchwey, Eds., pp. 187-192, Materials Research Society, Warrendale, Pa, USA, 2005.

[27] W. I. Abdel-Fattah, T. Jiang, G. E.-T. El-Bassyouni, and C. T. Laurencin, "Synthesis, characterization of chitosans and fabrication of sintered chitosan microsphere matrices for bone tissue engineering," Acta Biomaterialia, vol. 3, no. 4, pp. 503514, 2007.

[28] M. Borden, M. Attawia, Y. Khan, S. F. El-Amin, and C. T. Laurencin, "Tissue-engineered bone formation in vivo using a novel sintered polymeric microsphere matrix," Journal of Bone and Joint Surgery, vol. 86, no. 8, pp. 1200-1208, 2004.

[29] H. Yi, L. Wu, W. E. Bentley et al., "Biofabrication with chitosan," Biomacromolecules, vol. 6, no. 6, pp. 2881-2894, 2005.

[30] S. T. Koev, P. H. Dykstra, X. Luo et al., "Chitosan: an integrative biomaterial for lab-on-a-chip devices," Lab on a Chip, vol. 10, no. 22, pp. 3026-3042, 2010.

[31] T. Jiang, A Tissue Engineering Approach to Bone Regeneration Using Novel Hybrid Scaffolds Based on Natural Chitosan and Synthetic Poly(lactide-co-glycolide), University of Virginia, 2008.

[32] T. Jiang, W. I. Abdel-Fattah, and C. T. Laurencin, "In vitro evaluation of chitosan/poly(lactic acid-glycolic acid) sintered microsphere scaffolds for bone tissue engineering," Biomaterials, vol. 27, no. 28, pp. 4894-4903, 2006.

[33] T. Jiang, Y. Khan, L. S. Nair, W. I. Abdel-Fattah, and C. T. Laurencin, "Functionalization of chitosan/poly(lactic acid-glycolic acid) sintered microsphere scaffolds via surface heparinization for bone tissue engineering," Journal of Biomedical Materials Research A, vol. 93, no. 3, pp. 1193-1208, 2010.

[34] S. Kumbar, C. Laurencin, and M. Deng, Natural and Synthetic Biomedical Polymers, Elsevier Science, 2014.

[35] A. Aravamudhan, D. M. Ramos, J. Nip et al., "Cellulose and collagen derived micro-nano structured scaffolds for bone tissue engineering," Journal of Biomedical Nanotechnology, vol. 9, no. 4, pp. 719-731, 2013.

[36] S. G. Kumbar, U. S. Toti, M. Deng et al., "Novel mechanically competent polysaccharide scaffolds for bone tissue engineering," Biomedical Materials, vol. 6, no. 6, Article ID 065005, 2011.

[37] S. G. Kumbar and C. T. Laurencin, "Natural polymer-based porous orthopedic fixation screw for bone repair and regeneration," Google Patents, 2011.

[38] H. Mizutani and M. R. Urist, "The nature of bone morphogenetic protein (BMP) fractions derived from bovine bone matrix gelatin," Clinical Orthopaedics and Related Research, vol. 171, pp. 213-223, 1982.

[39] F. C. Bauer and M. R. Urist, "Human osteosarcoma-derived soluble bone morphogenetic protein," Clinical Orthopaedics and Related Research, vol. 154, pp. 291-295, 1981.

[40] M. R. Urist, A. Mikulski, and A. Lietze, "Solubilized and insolubilized bone morphogenetic protein," Proceedings of the National Academy of Sciences of the United States of America, vol. 76, no. 4, pp. 1828-1832, 1979.
[41] C. Laurencin, M. Attawia, L. Q. Lu et al., "Poly(lactide-coglycolide)/hydroxyapatite delivery of BMP-2-producing cells: a regional gene therapy approach to bone regeneration," Biomaterials, vol. 22, no. 11, pp. 1271-1277, 2001.

[42] H. Nie, W. S. Beng, Y. Fu, and C. Wang, "Three-dimensional fibrous PLGA/HAp composite scaffold for BMP-2 delivery," Biotechnology and Bioengineering, vol. 99, no. 1, pp. 223-234, 2008.

[43] K. W. H. Lo, K. M. Ashe, H. M. Kan, and C. T. Laurencin, "The role of small molecules in musculoskeletal regeneration," Regenerative Medicine, vol. 7, no. 4, pp. 535-549, 2012.

[44] N. R. Kübler, J. F. Reuther, G. Faller, T. Kirchner, R. Ruppert, and W. Sebald, "Inductive properties of recombinant human BMP2 produced in a bacterial expression system," International Journal of Oral and Maxillofacial Surgery, vol. 27, no. 4, pp. 305309, 1998.

[45] F. Wu and T. Jin, "Polymer-based sustained-release dosage forms for protein drugs, challenges, and recent advances," AAPS PharmSciTech, vol. 9, no. 4, pp. 1218-1229, 2008.

[46] K. W.-. Lo, H. M. Kan, K. M. Ashe, and C. T. Laurencin, "The small molecule PKA-specific cyclic AMP analogue as an inducer of osteoblast-like cells differentiation and mineralization," Journal of Tissue Engineering and Regenerative Medicine, vol. 6, no. 1, pp. 40-48, 2012.

[47] A. K. Howe, "Regulation of actin-based cell migration by cAMP/PKA," Biochimica et Biophysica Acta, vol. 1692, no. 2-3, pp. 159-174, 2004.

[48] A. K. Howe, "Cross-talk between calcium and protein kinase $\mathrm{A}$ in the regulation of cell migration," Current Opinion in Cell Biology, vol. 23, no. 5, pp. 554-561, 2011.

[49] S. S. Taylor, J. A. Buechler, and W. Yonemoto, "cAMP-dependent protein kinase: framework for a diverse family of regulatory enzymes," Annual Review of Biochemistry, vol. 59, pp. 971-1105, 1990.

[50] J. D. Whittard and S. K. Akiyama, "Positive regulation of cellcell and cell-substrate adhesion by protein kinase A," Journal of Cell Science, vol. 114, part 18, pp. 3265-3272, 2001.

[51] J. A. Buckwalter, "Articular cartilage: injuries and potential for healing," Journal of Orthopaedic and Sports Physical Therapy, vol. 28, no. 4, pp. 192-202, 1998.

[52] T. Hardingham, S. Tew, and A. Murdoch, “Tissue engineering: chondrocytes and cartilage," Arthritis Research, vol. 4, supplement 3, pp. S63-S68, 2002.

[53] R. B. Jakobsen, L. Engebretsen, and J. R. Slauterbeck., "An analysis of the quality of cartilage repair studies," Journal of Bone and Joint Surgery A, vol. 87, no. 10, pp. 2232-2239, 2005.

[54] X. Li, L. Jin, G. Balian, C. T. Laurencin, and D. G. Anderson, "Demineralized bone matrix gelatin as scaffold for osteochondral tissue engineering," Biomaterials, vol. 27, no. 11, pp. 24262433,2006

[55] T. Wang, J. H. Lai, L. H. Han, X. Tong, and F. Yang, "Chondrogenic differentiation of adipose-derived stromal cells in combinatorial hydrogels containing cartilage matrix proteins with decoupled mechanical stiffness," Tissue Engineering A, 2014.

[56] H. Jung, J. S. Park, J. Yeom, N. Selvapalam, K. M. Park, and K. Oh, "3D tissue engineered supramolecular hydrogels for controlled chondrogenesis of human mesenchymal stem cells," Biomacromolecules, vol. 15, no. 3, pp. 707-714, 2014.

[57] C. T. Laurencin and Y. Khan, "Science translational medicine," Regenerative Engineering, vol. 4, no. 160, pp. 160-169, 2012. 
[58] P. A. Sharp and R. Langer, "Promoting convergence in biomedical science," Science, vol. 333, no. 6042, p. 527, 2011.

[59] R. James, G. Q. Daley, and C. T. Laurencin, "Regenerative engineering materials, mimicry, and manipulations to promote cell and tissue growth," National Academy of Engineering, vol. 43 , no. 3, article 8, 2013.

[60] R. James, S. G. Kumbar, C. T. Laurencin, G. Balian, and A. B. Chhabra, "Tendon tissue engineering: adipose-derived stem cell and GDF-5 mediated regeneration using electrospun matrix systems," Biomedical Materials, vol. 6, no. 2, Article ID 025011, 2011. 

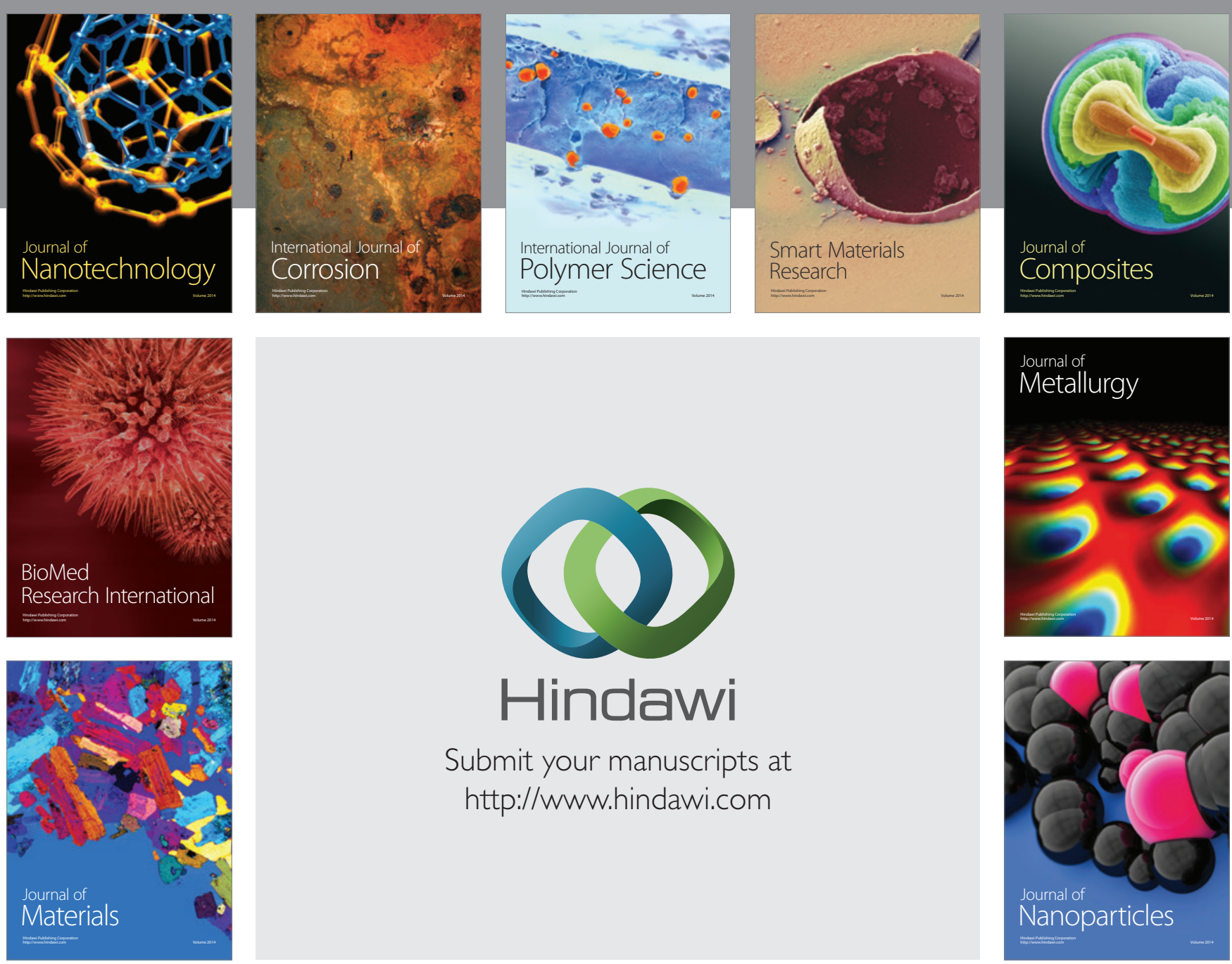

Submit your manuscripts at http://www.hindawi.com
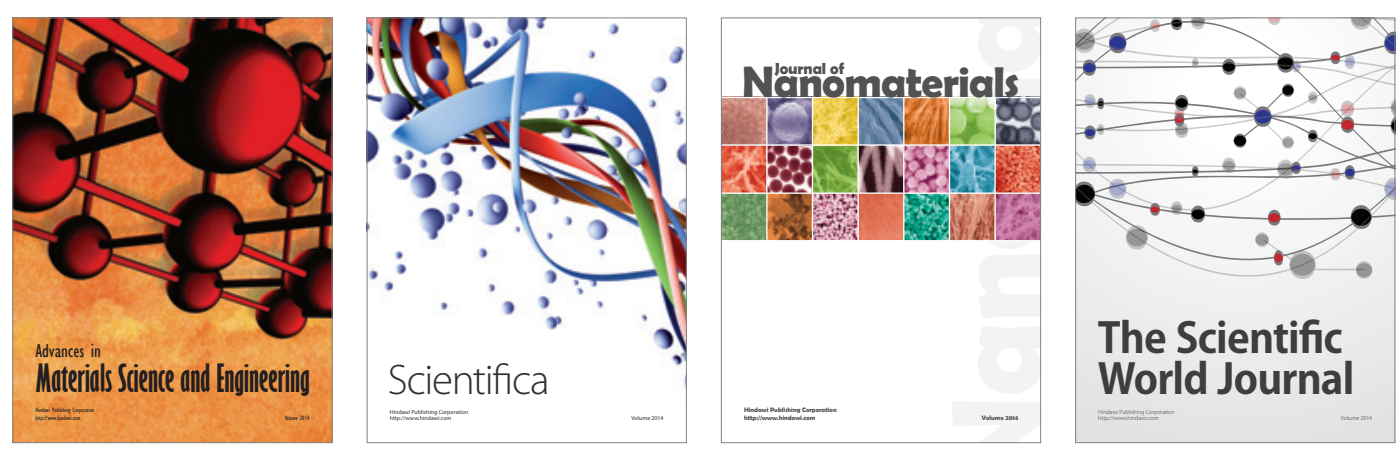

\section{The Scientific World Journal}
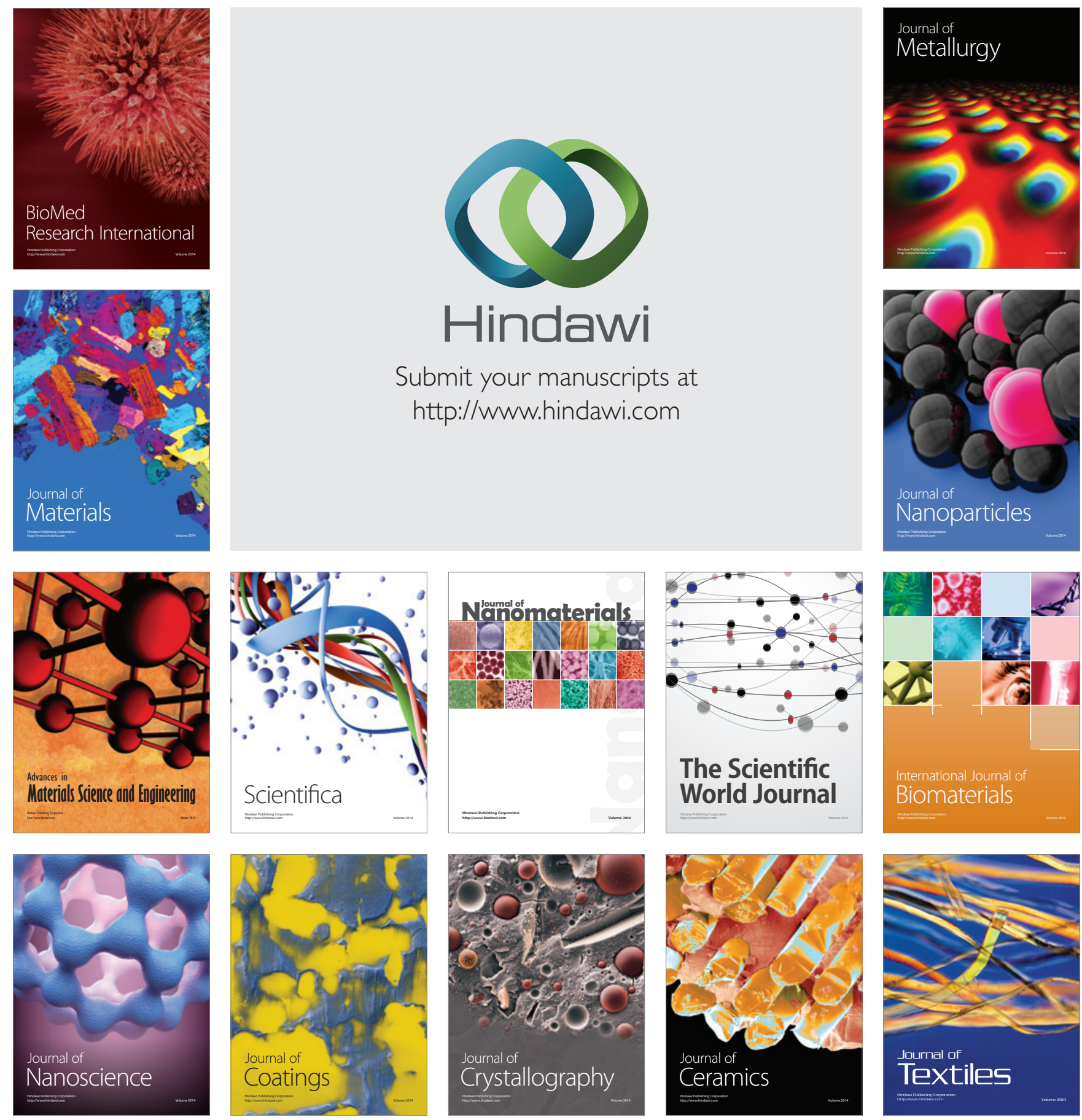